\title{
TANTRA, GÊNERO E SEXUALIDADE \\ E A TRADUÇÃO DO BUDISMO TIBETANO PARA O OCIDENTE
}

\author{
Bruno Carlucci*
}

\section{RESUMO}

Este artigo tem como objetivo problematizar as questões de gênero e sexualidade que se apresentam na tradução do budismo tibetano para o ocidente. A partir da noção de textos sensíveis (Karl SIMMS, 1997) e sua relevância para a tradução de textos ditos sagrados (Carlos Alberto GOHN, 2001), investigamos como questões sobre os papéis de gênero e de sexualidade são transmitidas e traduzidas ao longo da história do budismo tibetano e sua tradução do tantra budista indiano. Por fim, abordamos a visibilidade de mulheres como tradutoras e pesquisadoras na tradição budista e o seu potencial de resistência a um referencial falogocêntrico (Jacques DERRIDA, 1997). Palavras-chave: Tradução e gênero. Tradução de textos budistas. Textos sensíveis.

\section{TANTRA, GÉNERO Y SEXUALIDAD Y LA TRADUCCIÓN DEL BUDISMO TIBETANO PARA EL OCIDENTE}

\section{RESUMEN}

Este artículo tiene como objetivo problematizar las cuestiones de género y sexualidad que se presentan en la traducción del budismo tibetano hacia el occidente. A partir de la noción de textos sensibles (Karl SIMMS, 1997) y su relevancia para la traducción de textos dichos sagrados (Carlos Alberto GOHN, 2001), investigamos cómo las cuestiones sobre los roles de género y de sexualidad son transmitidas y traducidas a lo largo de la historia del budismo tibetano y su traducción del tantra budista indio. Por último, abordamos la visibilidad de mujeres como traductoras e investigadoras en la tradición budista y

* Doutorando em Linguística Aplicada no Instituto de Estudos da Linguagem (IEL) da Universidade Estadual de Campinas (UNICAMP). 
su potencial de resistencia a un referencial falogocéntrico (Jacques DERRIDA, 1997).

Palabras clave: Traducción y género. Traducción de textos budistas. Textos sensibles.

\section{TANTRA, GENDER AND SEXUALITY AND THE TRANSLATION OF TIBETAN BUDDHISM TO THE WEST}

\section{ABSTRACT}

This paper has the purpose to problematize sexuality and gender issues related to the translation of the Tibetan Buddhism into the west. Building on the notion of sensitive texts (Karl SIMMS, 1997) and its relevance to the translation of so called sacred texts (Carlos Alberto GOHN, 2001), we investigated how sexuality and gender roles have been transmitted and translated throughout the history of Tibetan Buddhism and its translation of Indian Buddhist tantra. Finally, we addressed women visibility (or lack thereof) as translators and scholars of Buddhism and their potential to offer resistance to a phallogocentric framework (Jacques DERRIDA, 1997).

Keywords: Translation and gender. Translation of Buddhist texts. Sensitive texts.

\section{INTRODUÇÃO}

Embora o ato sexual não seja considerado na perspectiva budista um pecado no sentido aferido pela ortodoxia cristã ocidental, nem seja proscrito para aqueles que não tomaram voto de celibato, o apego ao desejo e ao ato sexual são vistos como impedimentos para a iluminação. Ou seja, para que alcance o completo despertar, isto é, o estado de Buddha, a pessoa deve se capacitar de modo a que sua mente não mais esteja subserviente ao poder do desejo, incluindo o desejo sexual (Ignácio CABEZÓN, 1994, p. 6). Nessa perspectiva, o desejo por sensações prazerosas está relacionado aos estados aflitivos da mente presa ao samsara, fonte de insatisfação, que busca aplacar os anseios e medos de um eu ignorante de sua natureza vazia de existência inerente. Tal ignorância (em sânscrito avidyā) é a causa do apego e aversão e das demais perturbações mentais que contribuem para prender os seres sencientes no samsara (Alberto BRUM, 1992). 
Muito embora o voto de celibato não seja obrigatório para praticantes não monásticos, a conduta sexual é abordada em diferentes textos da tradição. Esses ensinamentos são inevitavelmente vinculados aos referenciais da cultura e da época em que esses textos foram produzidos acerca de noções de gênero e sexualidade que vão de encontro a muitas das mudanças culturais e sociais que têm ocorrido, principalmente no Ocidente, como o maior protagonismo das mulheres como agentes de transformação política e o reconhecimento do casamento igualitário, por exemplo.

Após a diáspora tibetana e a consequente disseminação do budismo tibetano pelo mundo, iniciou-se um esforço de tradução do extenso cânone tibetano para línguas ocidentais, em especial para a língua inglesa, uma vez que muitos departamentos de estudos budistas foram criados em universidades norte-americanas. O budismo tibetano que se desenvolveu nas últimas décadas nos Estados Unidos se tornou um molde para o budismo tibetano de outros países ocidentais, uma vez que o número de traduções de textos budistas tibetanos para o inglês é muito maior do que para outras línguas. As traduções do inglês norte-americano inclusive servem de fonte para traduções para o português (Bruno CARLUCCI, 2016) e o espanhol (Nicole MARTINÉZ-MELLIS, 2010), por exemplo.

Conforme apontado por uma pesquisa do Pew Research Center de 2007, estimou-se que 0,7\% da população norte-americana se considera budista. Apesar de constituir uma porcentagem pequena da população, esse dado torna o budismo a terceira maior religião daquele país, seguida do cristianismo $(78,4 \%)$, do grupo sem religião (10,3\%) e do judaísmo $(1,7 \%) .{ }^{1}$ Outra pesquisa realizada pelo jornal U-T San Diego, em 2012, apontou que $40 \%$ dos norte-budistas americanos vivem no sul da Califórnia. ${ }^{2}$

Num levantamento anterior realizado por Dunken Ryuken Williams e Christopher Queen (1999), cerca de um terço dos que se diziam budistas tinham diploma de nível superior e $60 \%$ se identificavam como eleitores do Partido Democrata, e o número de filiados ao Partido Verde ultrapassava o número de filiados ao Partido Republicano, numa pro-

Ver U.S. Religious Landscape Survey. Pew Forum on Religion \& Public Life, 2007.

Ver Rowe, Peter. Dalai Lama facts and figures. U-T San Diego, 2012. 
porção de três para um, denotando uma forte tendência progressista e liberal nessa população. A recepção e tradução do budismo tibetano, porém, não está alheia a uma série de tensões com os valores liberais e progressistas com frequência associados aos aderentes do budismo nos EUA, principalmente em relação aos direitos das mulheres e da população LGBT.

Um dos ensinamentos centrais do budismo se constitui pelos cinco preceitos (pañcaśīlāni), que incluem: não matar, não roubar, não ter uma conduta verbal inadequada, não incorrer em conduta sexual inadequada e não utilizar substâncias que intoxicam a mente (MASTER SHENG YENG, 2005). O voto de não incorrer em conduta sexual inadequada e as interpretações do que constitui ou não tal conduta variam de acordo com diferentes vertentes do budismo. Este artigo pretende abordar como tais questões se fizeram e fazem presentes na tradução de textos budistas, focando-se principalmente no cânone do budismo tibetano, levando em conta tanto a história da tradução do cânone budista indiano no Tibete quanto o fluxo mais recente de traduções para o inglês.

\section{TANTRA: UM GÊNERO SENSÍVEL}

Ao longo da história da tradução do cânone sânscrito para o tibetano, a questão sexual ganha grande proeminência, embora pouco discutida no fluxo do budismo tibetano para o ocidente, mas não completamente livre de polêmicas.

O budismo tibetano se insere na vertente chamada de mahāyāna, ou grande veículo, advinda do norte da Índia, cuja principal meta é a de libertar os seres sencientes do sofrimento, tendo como base a aspiração e a geração da mente altruísta (bodhiccita) e da sabedoria que compreende o vazio de existência inerente e a interdependência de modo que possa beneficiar a todos da forma mais efetiva possível (Andrew SKILTON, 2013). Há um forte caráter iniciático no budismo tibetano, uma vez que para acelerar esse processo o praticante pode se engajar no vajrayāna, ou veículo adamantino, também como conhecido ou tantrayāna, mediante transmissões e ritos específicos, embora ainda dentro do referencial mahāyāna (Andrew SKILTON, 2013). 
O mahāyāna em geral se baseia nos sutras do cânone em sânscrito, assim como, nos textos vinaya e tratados abhidharma. Resumidamente, os primeiros contêm registros que teriam sido concedidos oralmente pelo Buddha Śákyamuni, o segundo grupo também trata de ensinamentos atribuídos diretamente ao Buddha que se referem à disciplina ética e moral voltada principalmente para a vida monástica. Já o terceiro grupo de textos se constitui de tratados escritos por importantes instrutores budistas e teorias acerca da realidade e da cognição da realidade, que também encerram princípios éticos e morais para aperfeiçoar a cognição (Andrew SKILTON, 1994).

O vajrayāna já é um caminho que se baseia principalmente numa tradição oral, transmitida de guru a discípulo por meio de ritos especiais e cujas práticas meditativas envolvem um forte componente imagético, com mandalas, deidades masculinas e femininas, muitas vezes com muitas cabeças e braços, um grande detalhamento nas cores e, em muitos casos, em união sexual. Conforme explica Andrew Skilton (1994, p. 132): "O vajrayāna usa a magia ritual para alcançar as metas espirituais do budismo mahāyāna".

Muito dessa tradição também deriva do norte da Índia, principalmente da região de Kashmir, onde o tantra indiano, não somente budista, mas também vinculado a vertentes do hinduísmo, como o shivaísmo, teve um grande impulso em torno do século XVIII (PANDIT, p. 2, 1990), mais ou menos também no período da primeira difusão do budismo para o Tibete.

Embora seja comumente associada, traduzida e mercantilizada no ocidente como terapias sexuais, a palavra tantra em si tem como uma tradução possível, entre outras, "método" (Gavin FLOOD, 2006, p. 12). Trata-se de um método de meditação em que há uma série de visualizações externas de deidades e mandalas e internas (isto é, o próprio praticante se visualiza também como deidades masculinas e/ou femininas). Funcionando como uma espécie de tradução intersemiótica nos termos de Roman Jakobson (1959) de princípios da filosofia mahāyāna que comunicam camadas mais profundas e sutis da mente traduzindo-se em símbolos. Trata-se de um método adotado por diferentes escolas indianas, como já mencionado, portanto, cabe explicitar a sistematiza- 
ção presente no tratado tantraloka, realizada pelo shivaísta Ācārya Sri Abhinavagupta, em que se faz a seguinte distinção:

De acordo com a ciência do tantra, masculino e feminino são dois princípios universais do universo chamados de Shiva e Shakti. Ambos os princípios estão presentes dentro de cada indivíduo. Há três principais escolas de tantra: Kaula, Mishra, e Samaya. Os Kaulas, ou tantrikas da mão esquerda, adoram Shakti e seu modo de adoração envolve rituais externos, incluindo práticas sexuais na escola Mishra (misturada), a adoração interna é misturada com as práticas externas. O mais puro e mais elevado caminho do tantra é chamado de Samaya, ou caminho da mão direta. É puramente yoga, não tendo nenhuma relação com rituais ou qualquer forma de prática que envolva sexo (SWAMI RAMA, 1999, p. 248-249 apud M. G. CHITKARA, 2002, p. 26).

Pode-se ver, então, que a polêmica sobre as imagens sexuais utilizadas na simbologia do tantra não são exclusividade ao budismo, sendo provavelmente originadas nas tradições indianas que já existiam antes do aparecimento de escolas budistas. Mesmo a terminologia "mão direita" (dakșināāāra) e "mão esquerda" (vāmācāra) também é usada por autores budistas (Mark EPSTEIN, 2005), embora com menos frequência. As fortes reações que imagens sexuais podem suscitar no público, principalmente num contexto religioso em que o desejo sexual deve ser superado, se encaixam dentro da noção de sensibilidade textual de Karl Simms (1997, p. 75). Assim como no estudo do pudor no texto bíblico realizado por Luís Alves de Souza e Maria Flávia Figueiredo (2009), cabe também evocarmos Carlos Alberto Gohn (2001, p. 147) sobre o potencial da pesquisa de textos sagrados para os Estudos da Tradução, uma vez que "têm como matéria-prima materiais linguísticos que podem mostrar-se voláteis e explosivos, o que funciona, às vezes, como um atrativo extra para os que amam uma certa dose de adrenalina em sua pesquisa" (Carlos Alberto GOHN, 2001, p. 148). De fato, o tantra provavelmente constitui o aspecto mais volátil da religiosidade indiana, tanto hinduísta, quanto budista, com forte impacto na história de tradução e recepção do budismo no Tibete.

A história da tradução de textos budistas é marcada pela divisão entre as escolas do período das velhas traduções e das novas traduções 
(Bruno CARLUCCI, 2016). É muito difícil obter dados mais objetivos sobre a primeira difusão do budismo para o Tibete; sabe-se que alguns personagens desempenharam papéis importantes, mas é questionável o ponto em que esses personagens de fato estavam alinhados com um mesmo projeto de tradução e transmissão dos ensinamentos budistas.

De um lado, havia Shantarakshita e Kamalashila, eruditos (pandits) da universidade da Nalanda, um dos grandes centros de estudos e difusão do budismo na Índia, de outro um estudioso chinês chamado Ho-shang e um indiano chamado Padmsambhava. Embora seja comum em grupos com determinadas agendas políticas de tentar apagar ou desmerecer a diversidade e os conflitos inevitáveis entre as diferentes vertentes do budismo indo-tibetano, tanto em sua dimensão histórica, quanto em sua dimensão hermenêutica, há indícios históricos de que houve choques nesse período, principalmente no que concerne à interpretação do ensinamento que estava sendo traduzido. Esses aspectos foram demonstrados por pesquisadores como Andrew Skilton (2013), June Campbell (1999) e textos a respeito da história do budismo tibetano, como os Anais Azuis (deb ther sngon po), escrito por Go Lotsawa zhonnu Pel (1392-1481), abade do mosteiro de Karmarning e historiador do budismo, publicado em 1476 e traduzido por George Roerich (1996).

Shantarakshita e Kamalashila eram monges que, ligados à tradição dos sutras mahāyāna, como enfatizado pela universidade de Nalanda, preconizavam um caminho gradual que leva à iluminação, ou seja, um caminho que requer o esforço de vidas e vidas, atuando em prol de todos os seres. Como monges, eles estavam ligados à disciplina vinaya, uma coletânea de códigos morais para monges que inclui o voto do celibato. Ho-shang preconizava um caminho rápido e de iluminação súbita, sem necessidade de seguir os mesmos votos e a disciplina preconizada pelos pandits indianos de Nalanda. Ho-Shang acabou banido do Tibete, sob ordens do imperador tibetano, Khri-Shrong-Ide-Brston, após o debate de Samye entre ele e Kamalashila (Andrew SKILTON, 2013, p. 180).

Já Padmasambhava tinha grande ênfase no tantra, com interpretações literalistas das traduções dos textos e imagens tântricas da Índia, em que a perspectiva filosófica de Ho-shang, advinda de uma escola chinesa (C'an), se fazia presente num ensinamento chamado de dzogen, 
mesclando-se também com religião bön existente no Tibete antes da chegada do budismo (Andrew SKILTON, 2013, p. 181).

Em lendas e textos vinculados à escola nyingma (nome posterior aferido à escola que segue o cânone estabelecido por Padmasambhava e seus seguidores de interpretação literalista, significando "velhas traduções"), há lendas até da descrição de estupro ritualizado e coletivo de Yeshe Tsogyal, uma princesa que teria virado uma das consortes de Padmasambhava, como benéfico e conducente à iluminação de seus estupradores, como podemos ver no seguinte relato: "Yeshe Tosgyal é estuprada por um grupo de sete homens e enquanto é violada, ela canta para eles acerca das belezas do Dharma, imbuindo neles a maturidade espiritual e a libertação" (Natasha MIKLES, 2007, p. 31).

Há uma série de contos que descrevem uma relação entre Padmasambhava e Yeshe Tsogyal marcada de abusos por parte dele sobre ela, utilizando a sua posição de guru para que ela sirva de consorte para outros homens, como quando ele ordena que ela se entregue a um jovem no Nepal (Natasha MIKLES, 2007, p. 31). Vemos aqui um forte caráter patriarcal e misógino presente na história de parte do cânone budista tibetano, em que as mulheres muitas vezes são relegadas ao status de karmamudra ou kamamudra (selo ou instrumento do prazer sexual) ou, em outras palavras, meramente consortes que servem como instrumentos para que o homem se ilumine, destituídas de agência (Natasha MIKLES, 2007; June CAMPBELL, 2003).

Os que interpretam o cânone tântrico num viés literalista, incorrendo em práticas de sexo ritual, sacrifício de animais e uso de substâncias que intoxicam a mente são associados ao caminho da realização da mão esquerda (vāmāmārga), enquanto que os que consideram todas as imagens e narrativas, por vezes contraditórias e ambíguas dos textos tântricos, são considerados como aderentes do caminho de realizações da mão direita (dakșiṇāmārga), mantendo o tantra dentro do referencial dos votos dos cinco preceitos budistas (Serenity YOUNG, 2004, p. 135), a base da ética budista. O mesmo conflito que ocorre em sistemas tântricos indianos se traduz no sistema tântrico tibetano por meio de tal distinção, contribuindo para que haja uma reação de novas traduções dos textos e tratados sobre o tantra a partir do século $\mathrm{XI}$. 
Podemos ver o caráter volátil e os problemas e conflitos gerados em torno do choque entre as duas correntes de interpretação a partir da primeira difusão e tradução do tantra no Tibete no relato do monge-tradutor e historiador do século XV, Gö Lotsawa Zhonnu Pel (1949, p. 204): “A meditação sobre a realidade última tinha sido abandonada e muitas práticas nefastas apareceram, tais como práticas sexuais, assassinatos rituais, e práticas em que objetos eram enterrados com objetivo de ferir inimigos e outros problemas".

Yeshes Od, um rei da região oeste do Tibete, convidou Atisha para o Tibete. (DALAI LAMA apud Thomas LAIRD, 2006). A partir do núcleo formado pelo pandit indiano Atisha e o tibetano Rinchen Zangpo (a escola kadampa), ainda no século XI, a mesma ênfase de Shantarakshita e Kamalashila num caminho gradual e que não estivesse em contradição com ensinamentos básicos do budismo, como os cinco preceitos. Nas palavras de Andrew Skilton (2013, p. 181): "enfatizando que os imagens e rituais tântricos eram puramente simbólicos”. Nesse sentido, alinhando-se com a tradição do tantra da mão direita, em que a união sexual representa tão-somente a união de polaridades internas a ser visualizada por discípulos avançados em meditação. A partir daí a vertente não literalista ganha força no Tibete, coexistindo com a vertente literalista, porém ainda com um protagonismo praticamente nulo de mulheres nesse processo, uma vez que a estrutura da sociedade continuava patriarcal.

\section{AS DISCÍPULAS DO BUDDHA E AS TRADUTORAS DO BUDISMO}

Cabe ressaltar aqui que textos budistas indianos muitas vezes faziam menção ao fato de que não havia diferença entre o potencial de iluminação do homem e da mulher, marcando uma oposição à estrutura do sistema de castas na Índia antiga, em que à mulher era relegado um papel de servidão ao homem, conforme as normas de cada casta. Como afirma Janice Willis (1985, p. 73): “desde os seus primeiros dias como instrutor, o Buddha teria recebido o apoio de muitas mulheres, como mercadoras, cortesãs ricas, e rainhas".

Em sutras mahāyāna, como o Gaṇdavyūhasūtra (Douglas OSTO, 2008) e o Śrīmālādevīsutra (Brian BROWN, 2004), o Buddha aparecia ensinando mulheres; no caso do segundo texto, a principal discípula a 
receber o ensinamento daquele sutra é a rainha Srimala. Nos relatos lendários da tradição, o próprio sistema abhidharma teria sido formulado pelo Buddha, primeiramente para ensinar a sua mãe, Mayadevī, que teria se tornado uma deusa (devanī) após sua morte (Plínio TSAI, p. 8, 2017). O cânone budista difere de alguns escritos de outras escolas indianas, justamente por expressar claramente que tanto homens quanto mulheres podem alcançar a iluminação, enquanto em outras escolas indianas, esse era um assunto aberto ao debate e sem consenso (Padmanabh JAINI, 1991).

Entretanto, o acesso das mulheres indianas aos ensinamentos das diferentes escolas filosóficas e religiosas da Índia nem sempre foi igual ao dos homens. Embora houvesse casos excepcionais de mulheres ascetas e ordens como os jainistas aceitassem mulheres como monjas, foi a partir da institucionalização do budismo que um grande número de mulheres passou a ter maior acesso a uma vida puramente monástica, o que incomodou a sociedade indiana da época (Susan MURCOTT, 2006, p. 56). Nos relatos da tradição budista, a primeira pessoa a ter adotado votos monásticos teria sido a tia e mãe de criação do Buddha, Mahaprajapati. A esposa de Buddha, Yaśodharā, teria seguido pelo mesmo caminho após o retorno do Buddha Śákyamuni para pedir perdão por tê-la abandonado (Plínio TSAI, 2017, p. 209-211). Acredita-se em algumas tradições que Yaśodharā teria alcançado a libertação do ciclo de nascimentos compulsórios, tornando-se uma arhat (Ranjini OBEYESEKERE, 2009, p. 11).

No Tibete, mesmo quando um currículo monástico mais estabelecido se formou com a escola Kadampa, tendo sua hierarquia aperfeiçoada pela escola Gelugpa, no século XV (Alberto BRUM, 1992), assim como na Índia, também havia e há mosteiros femininos, entretanto não é de se estranhar que geralmente se traduza bhikṣun̄ (sânscrito) ou bikkhuni (páli) como nun em inglês ou freira em português, e não monja.

As freiras no catolicismo nunca tiveram os mesmos privilégios e direitos que os padres, não podendo oficiar missas, ou realizar casamentos, por exemplo. O referencial cristão para a tradução de bhikṣuṇ̄ no contexto tibetano denuncia a assimetria de poder que também existe na estrutura monástica tibetana, uma vez que pouquíssimas mulhe- 
res até hoje recebem o título de geshe ou lama, por exemplo, que se referem a graus mais avançados de estudos, provas e debates pelos quais passam os monges. Não há muitos textos de monjas tibetanas ou autoras budistas não monjas (upāsikās) que tenham recebido destaque no cânone budista indiano e tibetano, o que torna o trabalho de tradução de textos budistas extremamente voltado para quase sempre perspectivas masculinas.

Ademais, embora haja algumas lamas no Ocidente, como Lama Caroline, ${ }^{3}$ e muitas budistas não monjas que traduzem e fazem pesquisas aprofundadas da filosofia e da religião budista, tanto do mahāyāna, quanto do vajrayāna, como Elizabeth Napper (2003), Sofia Stril-Rever (2000), Vesna Wallace (2001), Janice Wyllis (2002), Ruth Sonam (2010), há pouca teorização por parte delas a respeito de sua prática tradutória de textos indianos e tibetanos antigos e medievais que por vezes possam conter relatos e linguagem sexista, assim como ainda há pouca problematização no campo das pesquisas sobre budismo na academia acerca da ausência de vozes femininas no budismo contemporâneo, exceto quando na função de tradutoras de textos ou intérpretes de homens. Vemos aqui um problema também presente na história da tradução no ocidente, como afirma Tina Krontiris (1992, p. 17-18 apud Sherry SIMON, 2005, p. 46): "A tradução oferecia a mulheres um envolvimento na cultura literária, tanto como produtoras, quanto como consumidoras, que não desafiasse diretamente o controle masculino daquela cultura".

Há, inclusive, denúncias de abusos nessa relação de poder entre o homem lama, guru, autor e a mulher tradutora/intérprete, discípula, como no caso das várias denúncias que têm aparecido nos últimos anos contra o Lama Sogyal Rinpoche. Mimi, um pseudônimo de uma das denunciantes que trabalhavam com ele e o auxiliavam em suas traduções, relata que outros chegaram a dizer-lhe sobre o abuso: "se ele te espancar, ou fizer sexo com você, ele está na verdade abrindo o caminho para a iluminação" (Gabrielle MONAGHAN, 2011).4 O referencial patriarcal e misógino da relação abusiva entre Padmasambhava e Yeshe

\footnotetext{
Ver: http://centrodedharma.ngalso.org/?master=lama-caroline

Ver http://www.trimondi.de/EN/Sogyal.htm
} 
Tsogyal como conducente à iluminação se traduz na relação abusiva e misógina de Sogyal com suas discípulas.

June Campbell (1999), 5 uma ex-monja e pesquisadora do budismo, relata ter sofrido abusos do Lama Kalu Rinpoche por anos, numa relação que teria se iniciado entre lama, guru e discípula e tradutora/intérprete, até que ele a transformou em sua kamamudra ou escrava sexual. Em sua denúncia ela relata inclusive que tinham lhe dito que uma consorte do lama que causara problemas a ele em sua vida anterior acabou morta após ele ter se irritado e feito alguns "ritos específicos" para matá-la.

June Campbell também denuncia comumente ter ouvido que as mulheres deveriam rezar para renascer como homens na próxima vida, pois somente num corpo masculino, elas seriam capazes de alcançar a iluminação. Na vertente literalista do tantra (ou tantra da mão esquerda) é comum a crença de que somente o homem pode alcançar a iluminação por meio de sua consorte, absorvendo a sua energia durante a atividade sexual, mas, ao mesmo tempo, retendo o sêmen de modo que ele suba para o cérebro e conduza a estados de êxtase permanente no homem (June CAMPBELL, 2002, p. 116).

A tradução e transmissão do budismo no ocidente, assim como na história do fluxo de tradução do Tibete, se torna um campo de batalha, em que o falo, para algumas dessas vertentes, é instrumento máximo e central para a iluminação, e, portanto, está acima até mesmo dos preceitos defendidos pelo Buddha histórico, seja em relação ao celibato no caso de monges ou em relação ao não praticar violência sexual no caso daqueles que tomam votos não monásticos. Nessa perspectiva, de um tantra falocêntrico, somente o falo pode compreender a realidade e os fenômenos e trazer o contentamento.

Assim como na história do pensamento ocidental, o falogocentrismo (Jacques DERRIDA, 1997, p. 46) domina, manipula, distorce e se impõe como o patriarca que vê na mulher apenas um instrumento para a legitimação, satisfação e tradução do seu desejo e a pune quando esta se recusa à hospitalidade. Refletindo sobre a tradução/transmissão do budismo tibetano para o Ocidente e sua carga patriarcal em muitos textos, June Campbell propõe transformar a transmissão/tradução de textos com linguagem sexista:

Ver https://www.independent.co.uk/arts-entertainment/i-was-a-tantric-sex-slave-1069859.html 
Um ponto vital para tais mudanças seria uma disposição de tolerar uma abordagem hermenêutica afinada com o conhecimento contemporâneo e os valores da cultura em que se situa. Isso só poderia ser feito por meio da reciprocidade entre os elementos percebidos do dualismo, notavelmente o masculino e o feminino e uma aceitação da diferença como determinante da cultura, ao invés de dualismo e semelhança como metáforas centrais de significância. As mulheres seriam vistas, então, não como um obstáculo, um complemento, ou mesmo como a personificação da transcendência, mas como um sujeito que se autodefine por direito (June CAMPBELL, 2002, p. 159).

Nesse sentido, é inevitável ao tradutor na pós-modernidade problematizar as representações e os direitos humanos de grupos historicamente oprimidos, indo de fato além do dogma, e aplicando as palavras atribuídas ao Buddha no Kālāma Sutta de que não se deve acreditar em algo só porque alguém disse, mas deve haver investigação e estudo para analisar a validade e aplicabilidade de determinado ensinamento em determinada situação.

Nesse ponto, o fato de os Estados Unidos terem se tornado o centro da política editorial de tradução dos textos escritos e orais do budismo tibetano no ocidente formou uma estranha aliança com a lógica neoliberal da pós-modernidade, em que os ensinamentos concernentes às noções de iluminação e impermanência, pontos chave da filosofia budista, foram adaptados a uma lógica do consumo imediato.

A aliança do falogocentrismo ocidental e neoliberal com o patriarcado tibetano feudal se traduziu num estranho híbrido de budismo fast food, que prega o individualismo e o conformismo com os problemas sociais, o que Ron Purser \& David Loy (2013) e Peter Doran (2018) chamam de McMindfulness. O budismo é reduzido a uma narrativa de autoajuda para que as pessoas possam produzir mais na sociedade do hiperconsumo.

No caso das traduções, podemos considerar que as dimensões políticas e coletivas do budismo se perdem num emaranhado de textos muitas vezes traduzidos sob uma suposta pecha não sectária e descontextualizada, que apaga as complexidades e conflitos da sociedade que produziu os textos, reduzindo-o também a um produto de fácil consumo, em que nenhuma problematização ou questionamento é bem-vindo. 
O debate filosófico e ético se dilui, como se tais diferenças fizessem parte apenas de uma sopa de letrinhas em que os impactos e questionamentos acerca do impacto social e político de determinadas práticas e crenças se perdem. Se pensarmos que a palavra dharma tem como possível tradução suporte, um não sectarismo consumista que dilui tudo num único produto se torna um adharma, algo que perde o seu suporte.

\section{CONSIDERAÇÕES FINAIS}

Como a acepção da palavra lotsawa (tradutor em tibetano) encerra, quem assume a posição de traduzir textos de outra cultura atua como "os olhos do mundo" da cultura receptora (Alexander Farrar THURMAN, 2006, p. 9). Por mais que muitas vezes sejam relegados a um papel subserviente, são os tradutores que possibilitam que o budismo renasça em outras terras, como nos EUA e no Brasil e, portanto, também têm uma responsabilidade e um impacto na construção de budismos brasileiros ou de budismos norte-americanos.

Cabe aqui, no entanto, evocarmos um referencial de empoderamento presente no próprio budismo, a lenda de Ārya Tārā, uma das deidades mais importantes do budismo indo-tibetano. De acordo com o relato mítico (JONANG TĀRĀNATHA, 2007, p. 5), embora extremamente dedicada aos preceitos budistas, monges homens teriam dito a Târā que ela jamais seria capaz de se iluminar enquanto mulher e que deveria, portanto, retornar como homem em suas próximas vidas. Tärā, então, jurou sempre renascer como mulher até alcançar a iluminação e assim o fez, por seu mérito próprio, sem ter de se tornar objeto, nem precisar de homem algum.

Nesse relato sobre as origens de Ārya Tārā podemos ver um princípio de resistência que existe desde os primórdios do budismo na Índia, apontando para o potencial de iluminação independente do gênero daquele que busca esse caminho. Como Jonang Tārānatha (2007) explicita, Ārya Tārā é uma deidade dotada de grande sabedoria que representa entre outras coisas a compaixão em ação no mundo, o potencial de transformação do sofrimento em felicidade para todos os seres, a agência que caracteriza a ética fundamental do budismo mahāyāna, em que a compaixão necessita da sabedoria e do discernimento para sua eficácia. 
Em tempos de lutas feministas, movimentos que lutam contra o assédio sexual como o \#metoo, demandam pelo reconhecimento do casamento igualitário, é inevitável que os tradutores se vejam na posição de problematizar a recepção de textos, narrativas e práticas adotadas por vertentes do budismo tibetano que possam causar sofrimento se importadas de forma acrítica e literal.

Assim talvez o budismo renasça nos países ocidentais com uma abertura à renovação e à reformulação quanto aos rígidos papéis de gênero que contradizem muitos dos pressupostos éticos que o fizeram se diferenciar de outras escolas indianas da época como um movimento reformador, levando em conta a dimensão hermenêutica e não literalista dos textos e imagens tântricas, assim como da literatura base dos pressupostos éticos e filosóficos do budismo, isto é, os sutras, o abhidharma e o vinaya. Ou como nas palavras do pandit do século VIII, Shantideva (2007, p. 190-94) em sua súplica pela felicidade e bem-estar de todos os seres: "Que todos os seres, em qualquer lugar, possam nascer no gênero que quiserem" e "que todos os seres possam ser felizes".

\section{REFERÊNCIAS}

BROWN, Brian Edward. The Buddha Nature: A Study of the Tathāgatagarbha and Ālayavijñāna. Delhi: Motilal, 2004.

BRUM, Alberto. A Libertação do Sofrimento no Budismo Tibetano Gelugpa. Brasília: Teosófica, 1992.

CABEZÓN, Ignácio. Prefácio à Edição Brasileira. In: NAGARJUNA. Traduzido por Manoel Vidal. São Paulo: Editora Palas Athena, 1994.

CAMPBELL, June. I was a tantric sex slave. The Independent. Publicado em 10 de fevereiro em 1999. Disponível em: <https://www.independent.co.uk/arts-entertainment/i-was-a-tantric-sex-slave-1069859.html>. Acesso em: 8 jun. 2018.

CAMPBELL, June. Traveller in Space: Gender, Identity and Tibetan Buddhism. Londres: Continuum, 2002.

CARLUCCI, Bruno. Continuum Tradutório: Considerações sobre a tradução indireta de textos budistas tibetanos para o português brasileiro. Transversal - Revista em Tradução, Fortaleza, v. 2, n. 2, p. 54-70, 2016. Disponível em: <http://www.repositorio.ufc.br/ bitstream/riufc/28665/1/2016_art_bcarlucci.pdf >. Acesso em 8 jun. 2018. 
CHITKARA, M. G. Kashmir Shaivism: Under Siege. Delhi: APG, 2002.

DERRIDA, Jacques. El Tiempo de una Tesis: Desconstrucción e implicaciones Conceptuales. Barcelona: Proyecto A ediciones, 1997.

DORAN, Peter. McMindfullness: Buddhism as sold to you by neoliberals. The Conversation, 2018. Disponível em: <http://theconversation.com/mcmindfulness-buddhism-as-sold-to-you-by-neoliberals-88338>. Acesso em: 6 jun. 2018.

EPSTEIN, Mark. Open to Desire: The Truth About What the Buddha Said. Nova Iorque: Gotham Books, 2006.

FLOOD, Gavin. The Tantric Body: The Secret Tradition of Hindu Religion. Nova York: Ibtaurus, 2006.

GÖ LOTSAWA ZHONNU PEL. The Blue Annals. Traduzido por George Roerich. Delhi: Motilal, 1996.

GOHN, Carlos Alberto. Pesquisas em torno de textos sensíveis: os textos sagrados. In: PAGANO, A. (Org.). Metodologias de pesquisa em tradução. Belo Horizonte: POSLIN/ FALE/UFMG, 2001, p. 147-170.

JAINI, Padmanabh. Gender and Salvation Jaina: Debates on the Spiritual Liberation of Women. Berkeley: University of California Press, 1991.

JAKOBSON, Roman. On linguistic aspects of translation. In: The Translation Studies Reader. Lawrence Venuti (Org.). Londres: Routledge, 113-118, 1959 (2000).

JONANG TĀRĀNATHA. The Origin of Tara Tantra. Nova Delhi: Library of Tibetan Works and Archives, 2007.

LAIRD, Thomas. Conversations with the Dalai Lama. Nova York: Grove Press, 2006.

LAMA, Caroline. Biografia. Disponível em: <http://centrodedharma.ngalso. org/?master=lama-caroline>. Acesso em: 8 jun. 2018.

MARTÍNEZ-MELIS, Nicole. Translating Buddhist Terminology: Ethnocentrism, Multiculturalism, and Interculturalism. In: Translation Today, v. 7, n. 1\&2, 2010. Disponível em: http://www.ntm.org.in/languages/english/vol7_tt.aspx. Acesso em 10/06/2018.

MASTER SHENG YENG. The Bodhisattva Precepts: Direction to Buddhahood. Taiwan: Dharma Drum Mountain, 2005.

MIKLES, Natasha L. A Tantrika in the Modern World: The Sexual Agency of Yeshe Tsogyal. In: The Monitor, 2007. Disponível em: <https://pt.scribd.com/document/117860953/ Tantrika-in-the-Modern-World-the-Sexual-Agency-of-Yeshe-Tsogyal>. Acesso em: 6 jun. 2018.

MONAGHAN, Gabrielle. Bad Karma - Rigpa's Sogyal. Sunday Times, 2011. Disponível em: http://www.trimondi.de/EN/Sogyal.htm. Acesso em: 8 jun. 2018.

MURCOTT, Susan. First Buddhist Women: Poems and Stories of Awakening. Berkeley: Parallax Press, 2006. 
NAPPER, Elizabeth. Dependent-Arising and Emptiness: A Tibetan Buddhist Interpretation of Madhyamika Philosophy. Boston: Wisdom Publications, 2003.

OBEYESEKERE, Ranjini. Yaśodharā, The Wife of the Bodhisattva. The Sinhala Yaśodharāvata (The Story of Yaśodharā) and the Sinhala Yaśodharāpadanaya (The Sacred Biography of Yaśodharā). Albany-NW: State University of New York Press, 2009.

OSTO, Douglas. Power, Wealth and Women in Indian Mahāyāna Buddhism: The Gandavyuha-sutra. Nova York: Routledge, 2008.

PANDIT. History of Kashmir Shivaism. Delhi: Utpal Publications, 1990.

Pew Forum. U.S. Religious Landscape Survey. Pew Forum on Religion \& Public Life, 2007. Disponível em: http://www.pewforum.org/2015/05/12/chapter-2-religious-switching-and-intermarriage/. Acesso em: 10 jun. 2018.

PURSER, Ron; LOY, David. Beyond Mcmindfulness. Huffington Post, 2030. Disponível em: <https://www.huffingtonpost.com/ron-purser/beyond-mcmindfulness_b_3519289. html $>$. Acesso em: 8 jun. 2018.

ROWE, Peter. Dalai Lama facts and figures. U-T San Diego, 2012. Disponível em: <http:// www.sandiegouniontribune.com/sdut-all-about-dalai-lama-2012apr16-story.html >. Acesso em: 10 jun. 2018.

SHANTIDEVA. Guide to The Bodhisattva's Way of Life: How to enjoy a life of great meaning and altruism. Traduzido por Neil Elliot. Glen Spey (Nova York): Tharpa Publications, 2007.

SIMMS, Karl. (Org.). Translating sensitive texts: linguistic aspects. Amsterdam, Atlanta: Rodopi, 1997.

SIMON, Sherry. Gender in Translation: Cultural Identity, and The Politics of Transmission. Londres: Routledge, 2005.

SKILTON, Andrew. A Concise History of Buddhism. Birmingham: Windhorse Publications, 2013.

SONAM, Ruth. The Three Principal Aspects of The Path: An Oral Teachings by Geshe Sonam Rinchen on Tsongkhapa's lam gyi gtso bo rnam gsum. Ithaca-NY: Snow Lion, 2010.

SOUZA, Luis Alves de; FIGUEIREDO, Maria Flávia. Do Beijo ao Abraço: O Pudor na Tradução de Textos Bíblicos. In: Discursividades. Disponível em: <http://cepad.net.br/ discursividade/EDICOES/05/Arquivos/Souza.pdf>. Acesso em: 06/06/2018.

STRIL-REVER, Sofia. Tantra du Kalachakra: le livre du corps subtil. Paris: Desclée de Brower, 2000.

THURMAN, Alexander Farrar. Prefácio. In: NINA, Ana Cristina Lopes. Ventos da Impermanência: Um estudo sobre a ressignificação do budismo tibetano no contexto da diáspora. São Paulo: EDUSP, 2006.

TSAI, Plínio. Introdução. In: PANDITA VASUBANDHU. Abhidharmakoshakarika. Comentários aos versos 1 a 10. Traduzido por Plínio Marcos Tsai. Valinhos: Editora ATG, 2017. 
TSAI, Plínio Marcos. Meditações: A Vida do Buddha. Valinhos: Editora ATG, 2017.

WALLACE, Vesna A. The Inner Kălacakra Tantra: A Buddhistic Tantric View of the Individual. Oxford: Oxford University Press, 2001.

WILLIAMS, Dunken Ryuken; QUEEN, Christopher S. (Orgs.). The New Buddhism: Some Empirical Findings in American Buddhism: Methods and Findings in Recent Scholarship. Curzon Press, 1999.

WILLIS, Janice D. Nuns and Benefectrasses: The Role of Women in the Development of Buddhism. In: Women, Religion and Social Change (Orgs.). Yasbeck Yvonne Haddad; Ellison Banks Findly. Nova York: New York State University Press, 1985.

YOUNG, Serenity. Courtesans and Tantric Consorts: Sexualities in Buddhist Narrative, Iconography, and Ritual. Londres: Routledge, 2004.

Submetido em: 29-6-2018

Aceito em: 9-11-2018 